\title{
UV-Irradiation Effect on the Photodegradation of Plasticized Poly (Ortho, Meta, and Para-Fluorostyrene) Isomers in Solid Films
}

\author{
Khalid E. Al Ani ${ }^{1}$ \& Mai Anabtawi ${ }^{2}$ \\ ${ }^{1}$ Department of Chemistry, Faculty of Science, Baghdad University, Jaderyh, Baghdad, Iraq \\ ${ }^{2}$ Departments of Chemistry, Faculty of Science, Hashemite University, Zarka, Jordan \\ Correspondence: Khalid E. Al Ani, Department of Chemistry, Faculty of Science, Jaderyh, Baghdad, Iraq. Tel: \\ 964-771-238-6136. E-mail: khalidalani44@yahoo.com
}

\author{
Received: August 13, 2012 Accepted: August 31, 2012 Online Published: September 26, 2012 \\ doi:10.5539/ijc.v4n5p62 \\ URL: http://dx.doi.org/10.5539/ijc.v4n5p62
}

\begin{abstract}
The photostability of thin films of poly (Fluorostyrene) isomers was studied by irradiation with UV-light, in presence of air at room temperature. The irradiated polymer films were exposed to different intervals of time and the degradation process was investigated with absorption, fluorescence and FT-IR spectroscopic methods. The influence of phthalate and terephthalate plasticizers on photo-oxidative degradation was also investigated. Blending with these plasticizers was found to decrease the stability of the irradiated polymers. The same observation was noticed in the photodegradation of other substituted polystyrenes films. The intensity of absorption was also found to increase with time of irradiation and in the intensity of a new absorption band at longer wavelength. In addition the formation on new fluorescence band at longer wavelength for the irradiated film is an evidence of photodegradation of the irradiated polymer films. The FT-IR spectra of irradiated polymers and for blended polymer films with phthalates and terephthalate, showed an increase in the absorption bands of these isomers indicating the possibility of degradation. The mechanism of photodegradation of these isomers was found to be similar to that of polystyrene. The order of photostability of these isomers was found that poly ( $p$-fluorostyrene) is the most stable isomer and, poly (o-fluorostyrene) is the lowest stable isomer towards irradiation effect.
\end{abstract}

Keywords: excimer fluorescence, poly fluorostyrene isomers, photodegradation kinetics, phthalate plasticizers

\section{Introduction}

The thermal and photostability of substituted polystyrenes is important both from practical and theoritical viewpoints (Boinon, Ainad-Tabt, \& Montheard, 1990; Bertini, Audisio, \& Kiji, 1994; Bertini, Audisio, \& Kiji, 1995; Al Ani, \& Ramadhan, 2008). The investigation of thermal behaviours of para-substituted polystyrenes is of interest withrespect both to preperation of new polymeric materials and to the industerial importance of these polymers (Zuev, Bertini, \& Audisio, 2001; Weir, Arct, \& Farahani, 1985; McNeill \& Coskun, 1989). Substituted polystyrenes are widely used in industry for many applications in our daily life. They have been used as polymeric reagents, solid phase for chromatography, electrical isolation, and solid phase absorbents.

The degradation of polymer materials on outdoor exposure can often be attributed to photochemical reactions arising from absorption of UV-radiation by polymeric chromophores, impunities like ketone groups, and hydroperoxide groups present on the polymer backbone. Ketones and hydroperoxide groups are more likely to be formed by air oxidation on moulding and synthesis of the polymer. Earlier studies have shown (Weir \& Milkie, 1979a; McNeill \& Coskun, 1987; Ranby \& Rabek, 1974) that substituted polystyrenes degrade under the exposure to UV-radiation in air through two processes: photolysis and photooxidation. Absorbed light of wavelength up to $300 \mathrm{~nm}$ causes breaking of chemical bonds and free radical formation. The initiation of free radicals formation is expected to result from the absorption by polymeric chromophores. A number of different photoproducts are reported. Hydroperoxides, carbonyl and hydroxyl compounds were the main products which resulted from the photo-oxidation of substituted polystyrenes films (Weir, Whiting, \& Arct, 1990; Mailhot, Jarroux, \& Gardette, 2000; Weir \& milkie, 1979b; Weir \& Milkie, 1979c).

Photodegradation of substituted polystyrenes is rather a complicated issue. A number of different photoproducts are formed, and a wide variety of mechanisms has been proposed. The substituted group in the styrene 
chromophores plays an important role in the mechanism of photooxidation and photodegradation reactions (Ranby \& Rabek, 1974; Mailhot, Jarroux, \& Gardette, 2000).

It was reported that polymeric additives accelerate the radiation-induced degradation of polystyrene and p-substituted polystyrenes films (Kaczmarek, 1995; Rabek, 1995). It was also found that the photo-stability of PS was reduced by the addition of bromine-containing flame retardants, and appeared to depend upon the chemical structure of the additive (Torikai, Kobatake, Okisaki, \& Shuyama, 1995). It was reported that the photodegradation of PS-containing carbonyl group was increase by the increase in time of irradiation. The changes of the average molecular weight in photo oxidized PS were produced as a consequence of chain dissociation by the Norrish Type II reaction (Choi, Jung, Sik, \& Cho, 1998).

In the present paper, the photo-oxidation of poly (fluorostyrene) isomers, and the effect of added plasticizers on the photostability were investigated with the following aims:

(1) to investigate the influence of ortho-, meta-, and para- substituent on the efficiency of photo-oxidation and photodegradation processes.

(2) to investigate the effect of added phthalates and terephthalate plasticizers on the photostability of these isomers.

(3) to compare the photostability of poly (fluorostyrene) isomers with that of polystyrene, and p-substituted styrene. The fluoro group was chosen as a substituent largely on accommodating electron withdrawing characteristics which would be expected to influence the stability of radicals produced, particularly those at the $\alpha$ - position of the polymer chain.

The substituted styrene polymers used in this study were assigned the following abbreviations: poly ( $o$-fluorostyrene) (o-PFS), poly ( $m$-fluorostyrene) $(m-P \mathrm{FS})$ and poly ( $p$-fluorostyrene) $(p$ - $P \mathrm{FS})$.

\section{Experimental}

\subsection{Materials}

The samples of ortho-fluorostyrene, meta-fluorostyrene and para-fluorostyrene monomers were supplied by Across-Organics with high purity. Before polymerization, they were distilled under reduced pressure in the presence of pure nitrogen and stored in the dark at $0.0^{\circ} \mathrm{C}$. Only spectroscopic grade dichloroethane (DCE) was used in preparation of these isomers, and in casting the solid films. It was found to give no detectable absorption in range $(250-400 \mathrm{~nm})$. It was purchased from Fluka GMBH and was used as received. The used plasticizers are dimethyl terephthalate (DMT), diethyl terephthalate (DET), dioctyl terephthalate (DOT), dibutyl phthalate (DBP) and dioctyl phthalate (DOP). These were of high purity of about $(99.8 \%$ ), and were purchased from Across-Organics and found to give no detectable absorption in rang 260-400 nm.

\subsection{Polymerization}

The poly ( $p$-fluorostyrene), poly ( $m$-fluorostyrene) and poly ( $o$-fluorostyrene) were prepared by free radical polymerization. A 1.0 gram of the monomer is dissolved in $25 \mathrm{ml}$ of DCE solvent, and was placed in a thick-walled test tube is necked down near the top. To this tube, $0.04 \mathrm{~g}$ azobisisobutyronitrile (AIBN) is introduced. $\mathrm{N}_{2}$ gas was pumped into this solution for few minutes, to eliminate the dissolved oxygen present in this solution. The sealed tube is placed in a water bath thermostated at $\left(65-70{ }^{\circ} \mathrm{C}\right)$, for 12 hours. Polymerization takes place slowly to give a colorless viscous solution. The tube is broken, and the viscous solution is added with stirring to $250 \mathrm{ml}$ methanol at room temperature, and a white fibrous precipitate was formed of the polymerized monomer. The precipitate was dissolved in $10 \mathrm{ml}$ DCE and reprecipitated as white fibrous solid by addition of $200 \mathrm{ml}$ methanol. The polymer is collected by filtration and washed repeatedly with methanol. The polymer is further dried under vacuum for 6 hours, at $293 \mathrm{~K}$, to eliminate the presence of solvent molecules.

\subsection{Preparation of Plasticized Polymeric Solid Films}

PFS isomers thin films with thickness of approximately $0.02 \mathrm{~mm}$ were prepared by solution casting of $20 \mathrm{wt} \%$ polymer in DCE on a spectroscopic window (quartz plate of $1.0 \mathrm{~mm} \times 20 \mathrm{~mm}$ diameter). Moreover, about 0.02 $\mathrm{mm}$ thick PFS isomers-plasticizer films, containing different wt $\%$ plasticizers were prepared by solution casting of $20 \mathrm{wt} \%$ polymer+added plasticizer, in DCE solvent. These films were used as to gain better insight into the possibility of photodegradation of the polymer during irradiation. The films were dried in a vacuum oven at 293 $\mathrm{K}$ for 6 hours, as to ensure the complete removal of solvent traces (Al Ani \& Suleiman, 2007).

\subsection{Absorption and Fluorescence Spectra Measurements}

The UV absorption spectra for PFS-isomers were recorded before and immediately after UV irradiation with a 


\section{Cary 100 Bio UV-visible Spectrophotometer at $298 \mathrm{~K}$.}

Fluorescence spectra were recorded on JASCO-FP 6500 spectrofluorometer for each of the prepared samples. The parameters were constant for all measurements, and the excitation wavelength was $265 \mathrm{~nm}$. The emission wavelength range was $270-500 \mathrm{~nm}$, and all fluorescence spectra for the solid films were obtained using a thermostated solid sample holder at $298 \mathrm{~K}$.

\subsection{Irradiation of Polymeric Solid Films}

PFS isomers solid films were exposed to different intervals of irradiation time in air, from (0.0-3 hours), using a JASCO-Spectrofluorometer with a built in Hydrogen-Xenon lamp (6808-J007A model number ESC-333), and supported with monochromator of holographic grating with 1800 groves $/ \mathrm{mm}$. Solid films were exposed to the same rate of irradiation intensity.

\subsection{Measurements of FT-IR-spectra}

The Fourier transform infrared spectroscopy system that was employed in this work was NICOLET-MAGNA-IR-560 spectrometer, while the transmission mode was employed in these measurements. The working wavenumber range of the spectrometer was from 4000 to $500 \mathrm{~cm}^{-1}$, with a resolution of $4 \mathrm{~cm}^{-1}$. The FT-IR spectra were recorded for the irradiated and the non-irradiated films, whereas the transmittance was plotted as function of the wavenumber.

\section{Results and Discussion}

3.1 UV-Absorption Spectra of Non-Irradiated and Irradiated Poly (O, M and P-Fluorostyrene) Isomers in Dichloroethane (DCE) Solution

The UV-absorption spectra of the PFS isomers in dichloroethane solutions before and after irradiation for three hours at $\lambda_{\text {ext }}=265 \mathrm{~nm}$, are shown in Figure 1 .

The absorption spectra for the three isomers, reveals absorption in the range of (260-280 nm), similar to those of polystyrene (Rao, 1975), and other substituted polystyrene (Al Ani \& Ramadhan, 2008), but they have a different structures in the shape of the absorption spectrum. Figure1 shows the absorbance changes which accompany the irradiation of $\left(1 \times 10^{-4} \mathrm{M}\right)$ solution of PFS isomers at $265 \mathrm{~nm}$. A gradual increase of absorbance is observed in the region (280-320 nm), as well as, an increase in the absorption intensity of a broad band at longer wavelength. Similar changes occur on irradiation of poly (4-methoxystyrene) (Ranby \& Rabek, 1974), and poly substituted styrene in dichloroethane solution.

The general characteristics of the absorption spectra of non irradiated and irradiated PFS-isomers plasticized with dimethyl terephthalate (DMT) are shown in Figure 2. 

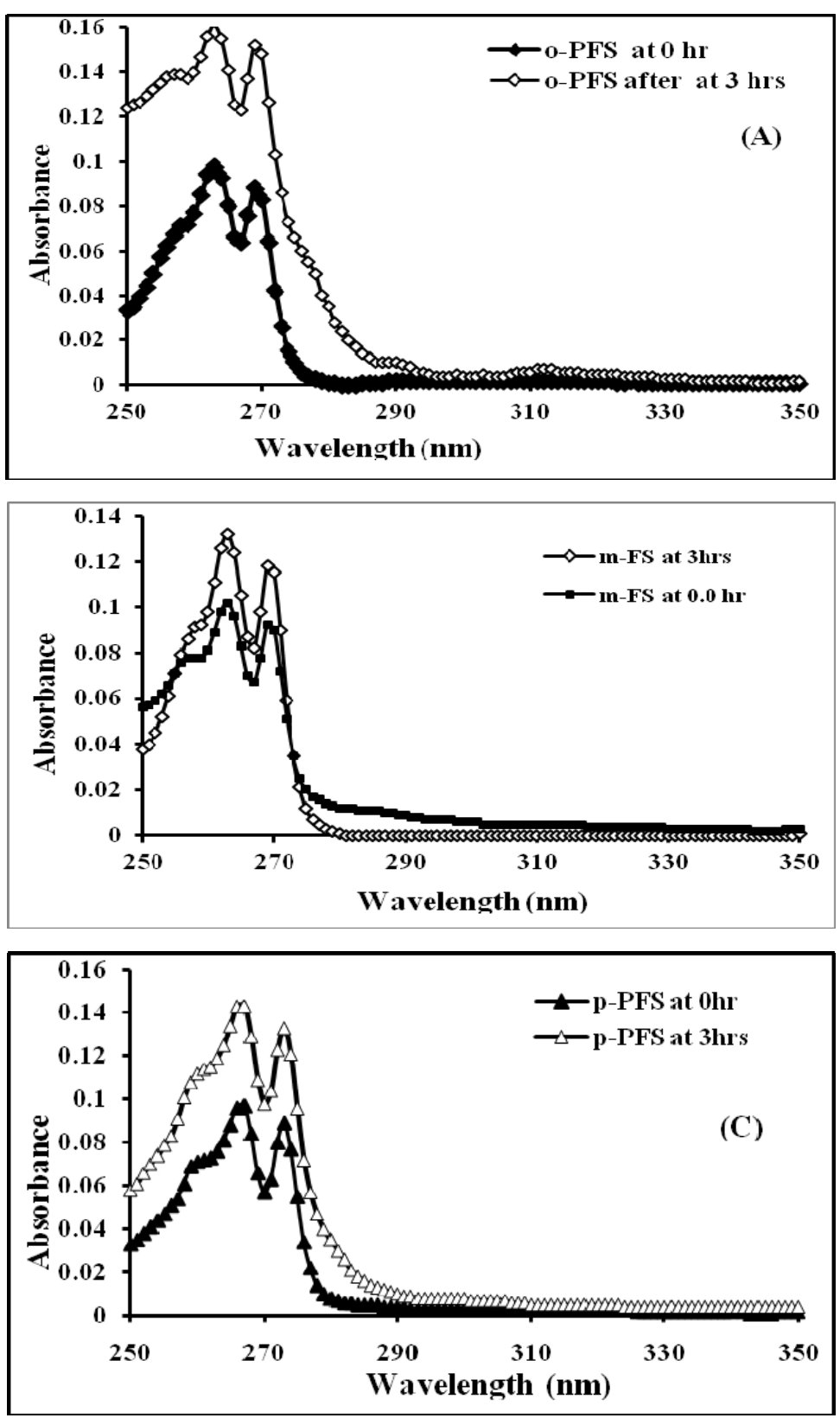

Figure 1. UV-Absorption spectra of, non-irradiated and irradiated for 3.0 hours of: (A) $o$-PFS, (B) $m$-PFS and (C) $p$-PFS, of $\left(1 \times 10^{-4} \mathrm{M}\right)$ solutions 

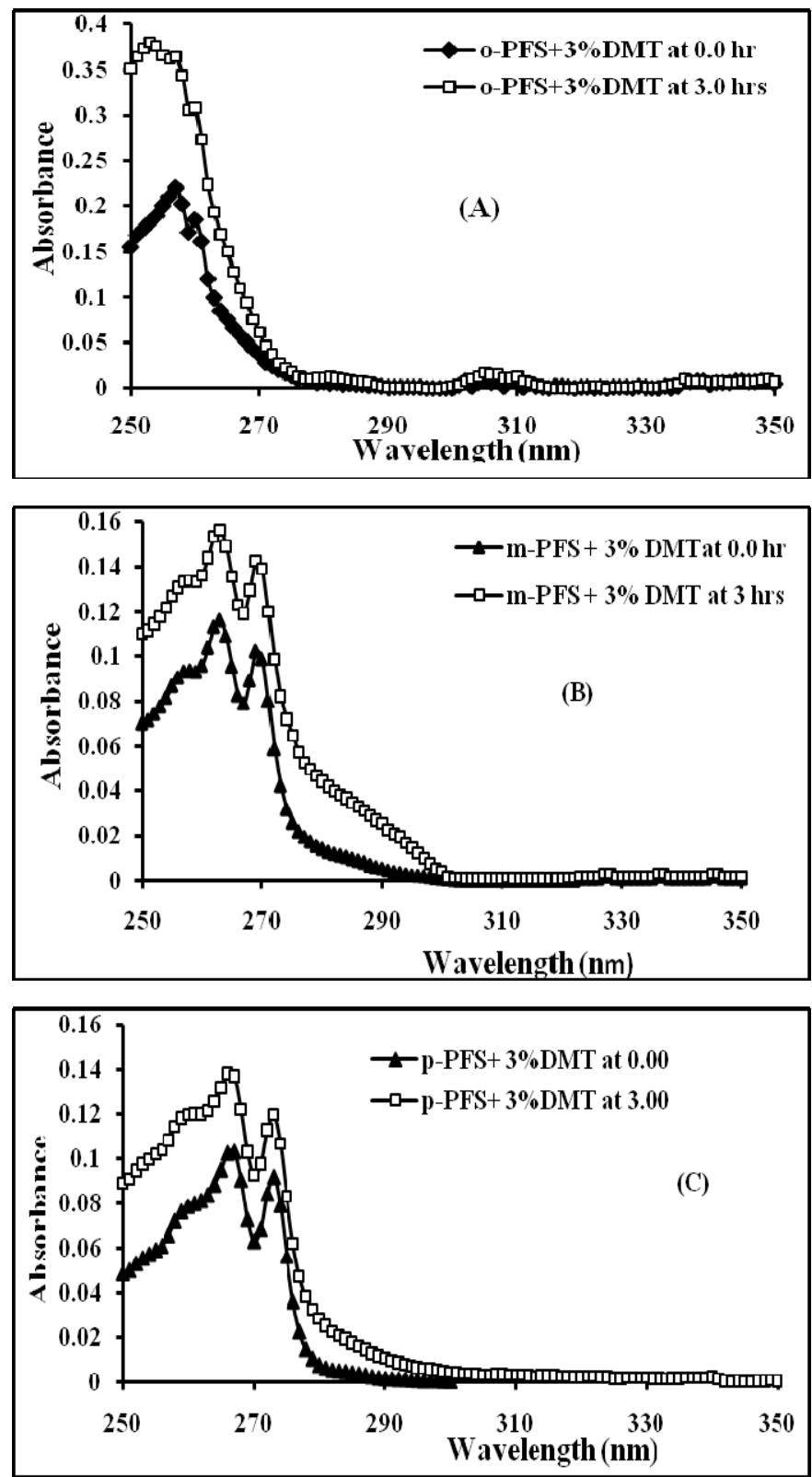

Figure 2. UV-Absorption spectra of non-irradiated and irradiated: (A) $o$-PFS blended with $3 \%$ DMT, (B) $m$-PFS blended with $3 \%$ DMT, and (C) $p$-PFS blended with $3 \%$ DMT

After UV-irradiation, the absorption spectrum of plasticized PFS was altered much more in comparison with those of irradiated pure isomers. Plasticized o-PFS isomer showed a higher increase in the intensity of absorption spectra, and a change in the structure of the absorption band than that observed with irradiated $m$-PFS and $p$-PFS isomers. It was reported that polyene structure compounds are among the compounds resulted from the irradiated poly substituted styrene, and absorb in the UV-region. Accordingly, plasticized o-photoproducts PFS showed a higher increase in the absorption band as well as a change in the shape of the spectrum (Al Ani \& Ramadhan, 2008).

In addition, the $o$-PFS solution undergo a small yellowish discoloration on irradiation, which is attributed to the formation of main-chain double bonds conjugated with the phenyl group along the polymer chain (Rabek \& Ranby, 1974). Extension of this conjugation ultimately leads to a bathchromic shift in the absorption spectrum, hence to the formation of colored solution of irradiated PFS isomers solutions. Similar results have been reported on halogenated polystyrenes and PS, showed an increasing in the intensity of the absorption spectra with the increase in irradiation time (Weir \& Milkie, 1979a). 
The spectral changes in the $(280-320 \mathrm{~nm})$ regions have been attributed to the presence of derivatives of fulvene and benzvalene which are formed by UV-photoisomerization of benzene ring in the polymer chains (Rabek \& Ranby, 1974). Furthermore, the alkylation of phenyl ring favors photoisomerization, whereas, halogen atoms in the ring inhibit photoisomerization. The formation of polyene structures in the polymeric chains is considered the result of hydrogen abstraction from the carbon atom in position $\beta$ - of the phenyl group.

It has been reported that Irradiation of poly ( $p$-chlorostyrene), poly ( $p$-bromostyrene), poly ( $p$-fluorostyrene) and polystyrene films under identical conditions, reveals that both poly ( $p$-chlorostyrene), poly ( $p$-bromostyrene) undergo more rapid photodegradation than that of polystyrene. On the other hand, the irradiated poly ( $p$-fluorostyrene) film, showed a higher stability than that observed in the irradiated polystyrene film, presumably the result of the positive conjugative effects of $\mathrm{Br}$, and $\mathrm{Cl}$ groups on the phenyl group absorption around $260 \mathrm{~nm}$ (Weir \& Milkie, 1979a). The effect of increase in the intensity of absorption bands of the three isomers was fond to be in the order $o$-PFS $>m$-PFS $>p$-PFS, indicating that $p$-PFS is most stable isomer towards UV-irradiation.

\subsection{Effect of UV-Irradiation on Fluorescence Spectra of Pure and Blended PFS-Isomers with Phthalates and Terephthalate Plasticizers in Solid Films}

The effect of UV-irradiation on degradation of polystyrene and substituted polystyrene receives a considerable attention, mainly due to their industrial importance, (Beak \& Messer, 1969; Al Ani \& Hawi, 2009). However, the photodegradation of some substituted polystyrene has been studied extensively but no work on photodegradation of plasticized PFS isomers has been reported in solid films. Blending these isomers with of phthalate and terephthalate plasticizers in solid films, would result in quenching of both monomer and excimer emissions and in increasing in the intensity of a new fluorescence band at longer wavelength. Different percentages of these plastizers were used in blending of the PFS isomers. Each film was irradiated for several intervals of time by the same source of light with $\left(\lambda_{\text {ext }}=265 \mathrm{~nm}\right)$, and under the same conditions.

The fluorescence spectra were obtained for pure PFS isomers films, photo-irradiated, as well as non-irradiated polymer solid films, and are presented in Figure 3.

As shown in Figure 3, the dotted spectra show the main fluorescence band of non-irradiated poly $(o, m$, and $p$-fluorostyrene) isomers solid films. The main absorption band consists of a very weak monomer fluorescence band, and a strong excimer fluorescence band at longer wavelength. The excimer fluorescence bands of the PFS-isomers are centered at about, $o$-PFS $(\lambda=314 \mathrm{~nm}), m$-PFS $(\lambda=313 \mathrm{~nm})$ and $p$-PFS $(\lambda=322 \mathrm{~nm})$. Irradiation of the polymeric films of these isomers at different exposure time, $(0-150 \mathrm{~min})$, was accompanied by the gradual quenching in the intensity of the excimer band. However, the excimer fluorescence band of $o$-PFS shifts from (314 nm to $316 \mathrm{~nm}$ ), and $m$-PFS excimer fluorescence band shows shift from (313 nm to $316 \mathrm{~nm}$ ), and $p$-PFS excimer fluorescence band shows shift from $(322 \mathrm{~nm}$ to $332 \mathrm{~nm})$. It is more likely that this red shift occurs as result of photodegradation of the polymeric chains, and can be attributed to the formation of conjugated double bonds along the polymer chain during the photodegradation by hydrogen abstraction process (Lacoste, Carlson, Falicki, \& Wiles, 1994). The fluorescence band shift of these isomers is in good agreement with that reported with irradiated polystyrene (David et al., 1978), and other poly (substituted styrene) films (Subramanian, 2002). It has been reported that the spectral shift and the fluorescence quenching of irradiated polymer film might be attributed to the energy transportation of the oxides formed by the photooxidation of polymeric chromophores by UV-radiation (Jensen \& Kops, 1981). Several reports have studied the photo-oxidation of polystyrene by fluorescence spectra and proposed that the quenching of polystyrene fluorescence was attributed to the quenching effect of the peroxides formed during the irradiation of polymeric films (Wu, Liu, \& Dai, 1984; Szwarc, 1976; Lucas \& Porter, 1989; Weir, 1978). 

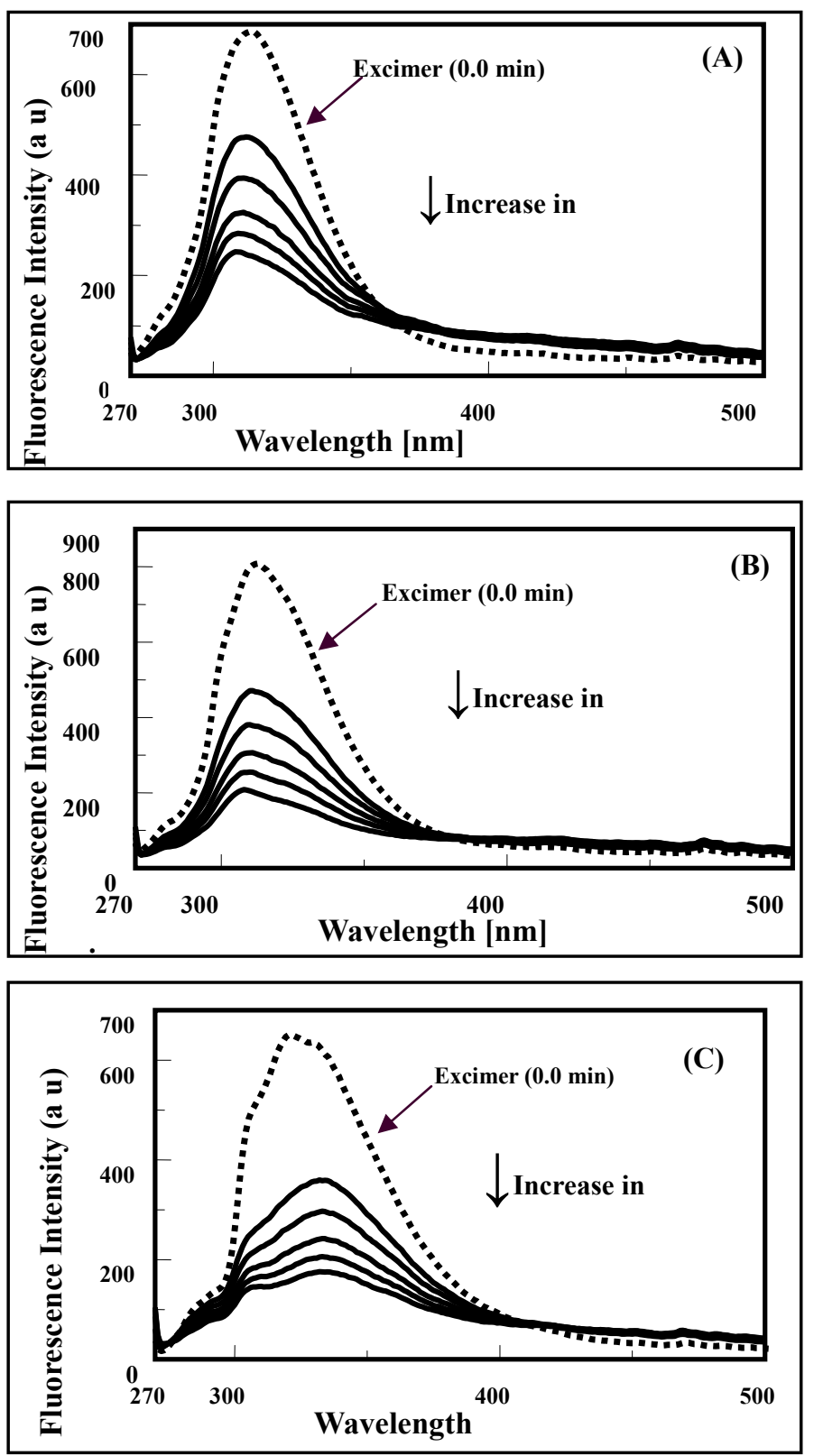

Figure 3. Fluorescence Spectra of irradiated solid films of (A) $o$-PFS, (B) $m$-PFS and (C) $p$-PFS at the exposure time $(0.0,40,90,110,130, \& 150 \mathrm{~min})$

The effects of exposure time of plasticized $o$-PFS, $m$-PFS and $p$-PFS-isomers on fluorescence spectra with $(1 \%$, $3 \%$ and $5 \%$ ) of DOT plasticizer in solid films were measured at $298 \mathrm{~K}$ and are shown in Figure 4 . All blended films were irradiated at $265 \mathrm{~nm}$ for different intervals of time (0.0-135 min), at room temperature. An effort was made to obtain almost all solid films with the same thickness of about $0.02 \mathrm{~mm}$. 

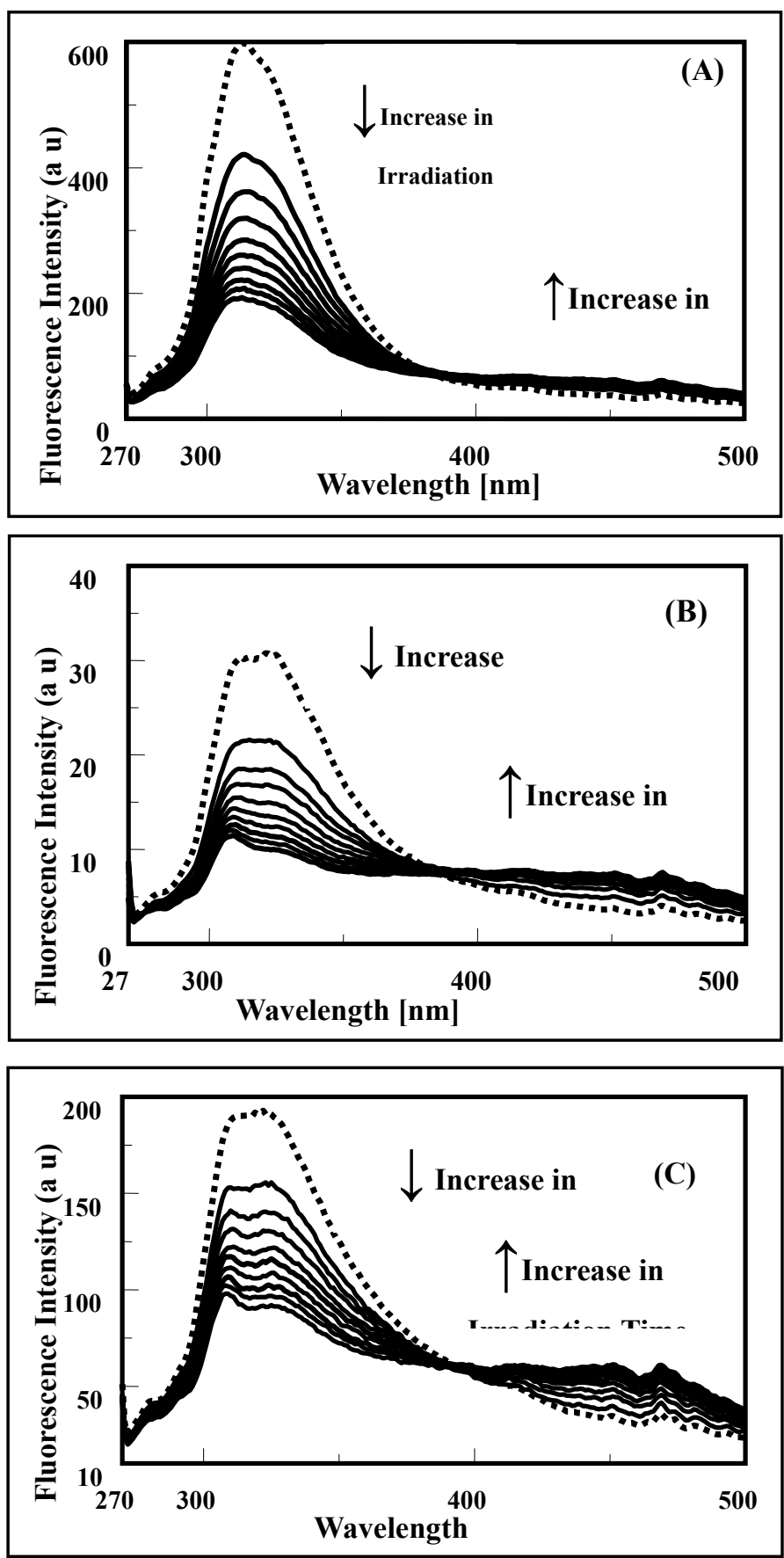

Figure 4. Fluorescence spectra of irradiated (m-PFS) solid films, blended with, (A) $1.0 \%$, (B) $3.0 \%$ \& (C) $5.0 \%$ DOT plasticizer, irradiated at different intervals of time [0-135] min

The fluorescence spectra of plasticized PFS isomers in solid films did not show any exciplex fluorescence emission, which indicates that, the formed energy transfer complex between the excited polymer chromophore and plasticizer molecule is not stable enough to give exciplex emission.

The irradiation of plasticized PFS-isomers solid films in presence of air, showed a gradual decrease in excimer emission accompanied with the appearance of new fluorescence broad band without clear maxima at longer wavelength. The new fluorescence broad band for DOT blended (o-PFS) appeared at about $\left(\lambda_{\max }=413 \mathrm{~nm}\right)$, and for $\left(m\right.$-PFS) appeared at about $\left(\lambda_{\max }=468 \mathrm{~nm}\right)$, and at about $\left(\lambda_{\max }=469 \mathrm{~nm}\right)$ for $(p$-PFS). Moreover, it can be noted that the intensity of the new broad band was increased with the increase in time of irradiation and with the increases in the amount of added plasticizer. On the other hand the excimer fluorescence intensity was decreased 
with the increase in the irradiation time and with the increase in the amount of added plasticizers. We believe that this broad band appeared as result of the formation of new compounds from the photo-oxidation and photodegradation processes of irradiated PFS isomers, indicating the possibility of formation of polyene unit structures and possibly other oxygen containing compounds.

The decrease of excimer fluorescence during irradiation is an indication for photooxidation of polymer chains, as well as chain scission. An isosebastic point was observed in the photo-irradiation of plasticized PFS isomers as in Figure 4 (A, B, and C). As can be seen from these plots, one can expect the occurrence of two major processes by the increase in time of irradiation; photodegradation process which was noticed by the gradual increase in the intensity of a new broad band at longer wavelength, and the quenching of the excimer fluorescence emission. From the fluorescence spectra of irradiated of plasticized PFS-isomers, a small red shift was noticed in the maxima of the excimer fluorescence bands.

\subsection{Kinetics and Mechanism of Photodegradation of PFS-Isomers in Solid Films}

The kinetic treatments to the fluorescence quenching of PFS isomers in solid films by the increase in the amount of added plasticizers, and by the increase in irradiation times at room temperature, are studied by applying the $\mathrm{Al}$ Ani-Hawi relation (Al Ani \& Hawi, 2009; Al Ani \& Ramadhan, 2010a; 2010b). They have formulated a new relation that can be used to study the kinetic treatments to the decrease of fluorescence quenching of PFS isomers in solutions by the increase in the amount of added plasticizers and by the increase in irradiation times at room temperature.

The ratio of $I^{o}[E X]^{*} /\left[[E X]^{*}\right.$ was found to increase by the increase in irradiation time to polymeric solution. $I^{o}[E X]^{*}$ is the intensity of excimer fluorescence of pure or doped polymer at zero time of irradiation, whereas, $I[E X]^{*}$ is the intensity of excimer emission of pure or doped polymer at different intervals of exposure time.

$$
I^{o}[E X] * / I[E X]^{*}=1+\left(\left(k_{P Q}^{\prime}\right) x A\right)(t)
$$

We can write:

$$
I^{o}[E X] * / I[E X] *=1+\left(k_{P Q}\right)(t)
$$

Where $[A]=$ number of (photons/s) absorbed by polymeric chromophores.

$t=$ time of irradiation in $\mathrm{s}$.

$k_{P Q}^{\prime}=$ rate constant

$k_{p q}=\left(\left(k_{P Q}^{\prime}\right) x A\right)=$ photo-quenching rate constant.

In the photo quenching processes, if we assume that the number of photons released from the light source and absorbed by polymer chromophores is constant (A), then, according to Equation (2), $I^{o}[E X] * / I[E X]^{*}$-values was plotted against time of irradiations $(\mathrm{t})$. From the plots, the photo-quenching rate constant $\left(k_{P Q}\right)$ values and $I^{o}[E X]$ $* / I[E X] *$ ratios were calculated and were used to estimate the efficiency of photo quenching and photodegradation processes for pure and blended isomers in solution. An Example of the kinetic treatments of the effects of irradiation time and plasticization on the fluorescence spectra is the irradiation of $o$-PFS films blended with DMT, DET, DOT, DBP and DOP, for (0-135 min), as shown in (Figure 5 \& Figure 6). 

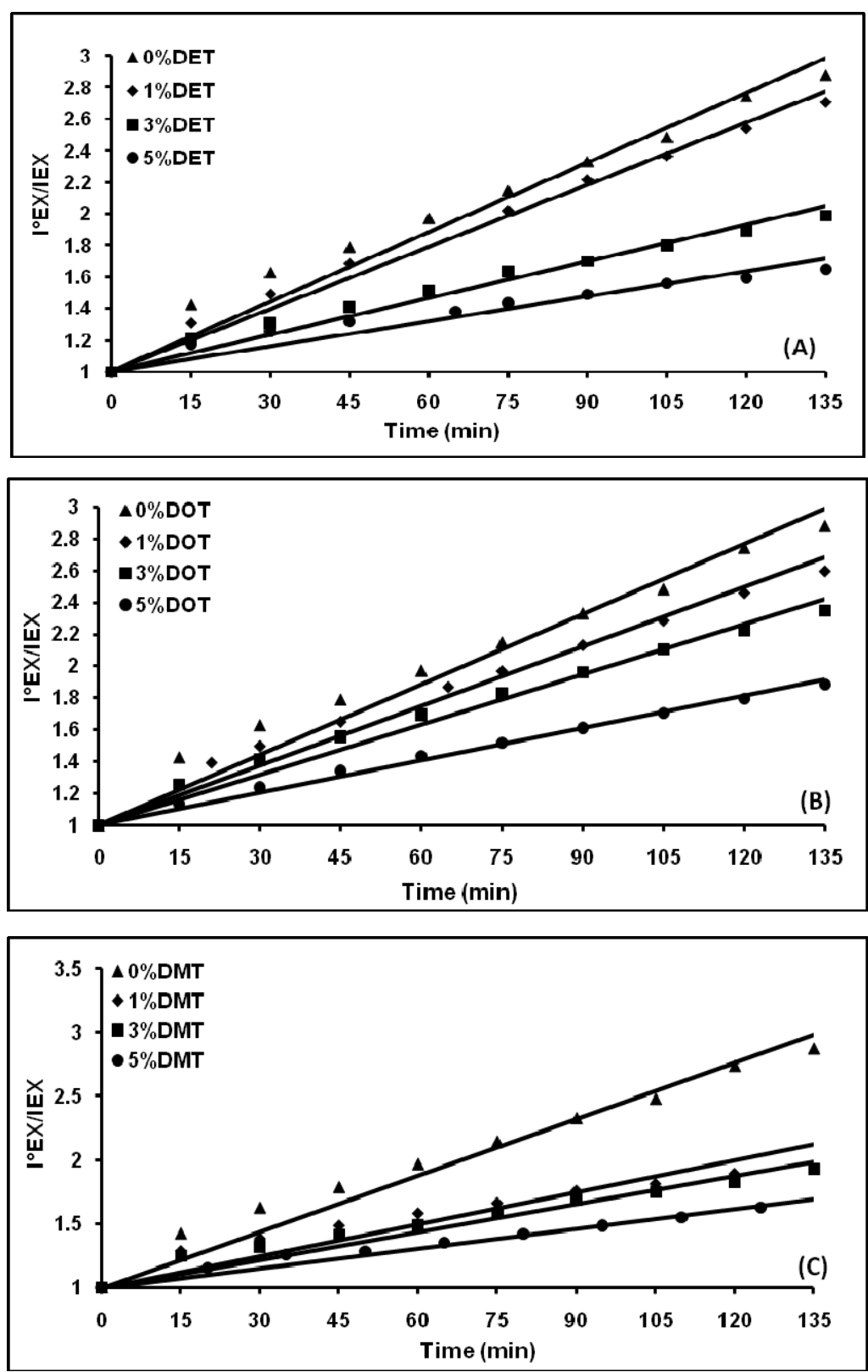

Figure 5. Plot of $\left(\mathrm{I}_{\mathrm{EX}}^{\circ} / \mathrm{I}_{\mathrm{EX}}\right)$ fluorescence ratio of non-plasticized and plasticized (o-PFS) solid films blended with different percentages of terephthalate plasticizers, (A) DET, (B) DOT and (C) DMT, plotted against exposure time $(0-135 \mathrm{~min})$ 

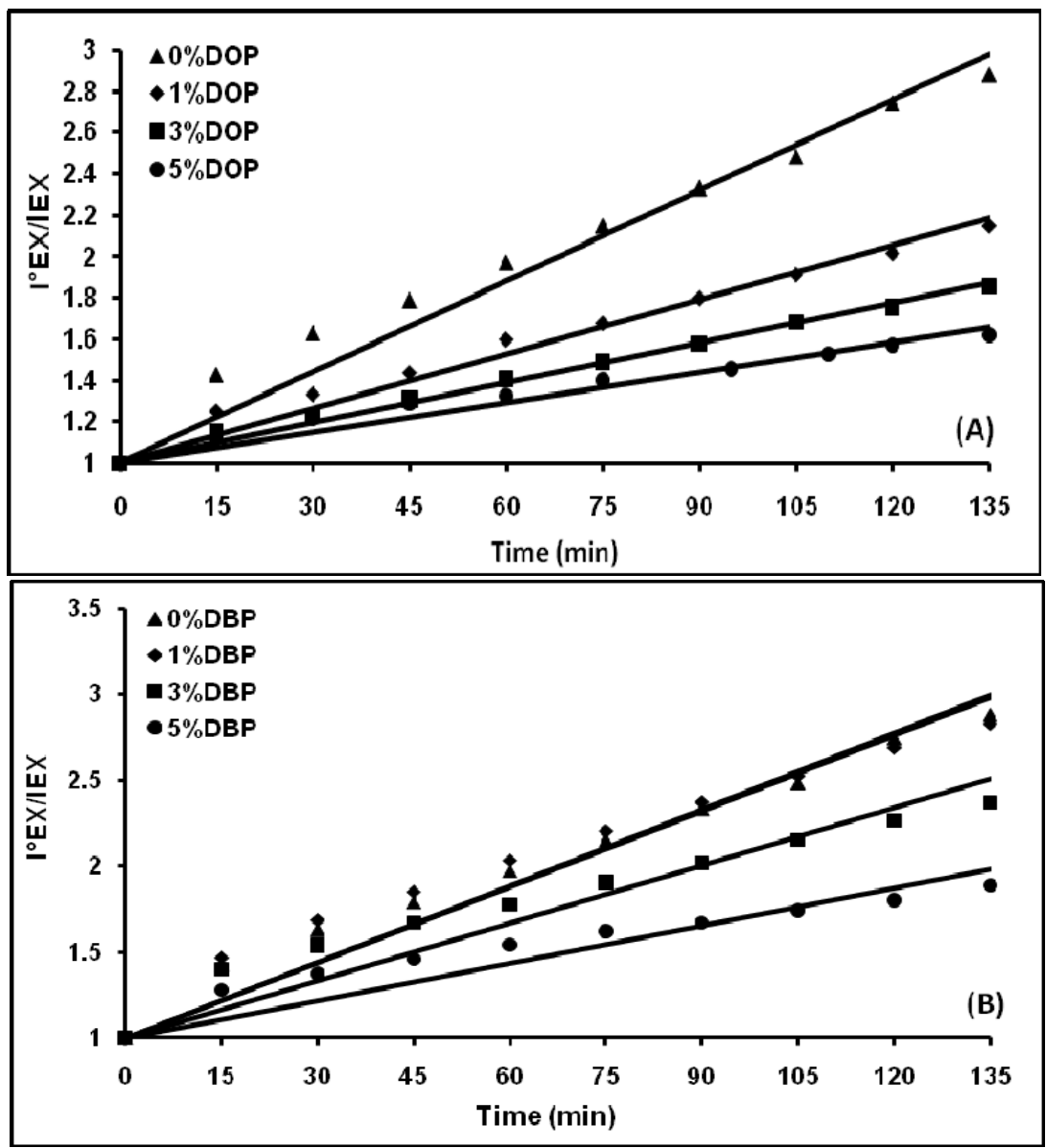

Figure 6. Plot of $\left(\mathrm{I}_{\mathrm{EX}}^{\mathrm{o}} / \mathrm{I}_{\mathrm{EX}}\right)$ fluorescence ratio of non-plasticized and plasticized o-PFS solid films blended with different percentages of phthalate plasticizers, (A) DOP, and (B) DBP, and is plotted against exposure time, $(0-135 \mathrm{~min})$

As can be seen from (Figure $5 \&$ Figure 6), the efficiency of photo quenching which is represented by the intensity of fluorescence ratio $\left(\mathrm{I}_{\mathrm{EX}}^{\mathrm{o}} / \mathrm{I}_{\mathrm{EX}}\right)$ was found to increase by the increase in exposure time and to decrease by the increase in the amount of blended plasticizers. The increase in the fluorescence quenching ratio by the increase in irradiation time may be attributed to the increase in the rate of the photodegradation and photooxidation processes. It is more likely, and as has been reported in the degradation of polystyrene (Kaczmarek, 1995), and substituted polystyrene (Al Ani, Ramadan, \& Ahmed, 2006; Tami et al., 1996), we can assume that cross-linking, chain scissions, and formation of oxygenated compounds that are initiated by proxy radicals are the major processes that result from the irradiation of PFS isomers. The same observations were observer in the photo quenching of excimer fluorescence; pure and blended $o$-PFS and $p$-PFS isomers by the increase in UV-exposure time at $\left(\lambda_{\text {ext }}=265 \mathrm{~nm}\right)$. The photo quenching ratio and the photo quenching rate constant $\left(\mathrm{k}_{\mathrm{PQ}}\right)$ values for plasticized PFS isomers were calculated by using $\mathrm{Al}$ Ani Hawi Equation (1) and are shown in Table 1. 
Table 1. Relative intensities of the excimer ratio $\left(\mathrm{I}^{\mathrm{o}}{ }_{\mathrm{EX}} / \mathrm{I}_{\mathrm{EX}}\right)$, and fluorescence photo quenching rate constant values $\left(k_{\mathrm{PQ}}\right)$ of irradiated pure and blended $(o$-PFS) films

\begin{tabular}{|c|c|c|c|c|c|}
\hline$\lambda_{\text {(emiss.) }}(\mathrm{nm})$ & Polymer & Plasticizer (\%) & Time (min.) & $\left(\mathrm{I}_{\mathrm{EX}}^{\mathrm{o}} / \mathrm{I}_{\mathrm{EX}}\right)$ & $k_{\mathrm{PQ}}$ \\
\hline 314 & $o$-PFS & $0.0 \%$ & 135 & 2.877349 & 0.0147 \\
\hline \multicolumn{6}{|c|}{$o-\mathrm{PFS}+\% \mathrm{DMT}$} \\
\hline 315 & $o$-PFS & $1.0 \%$ & 135 & 1.985193 & 0.0083 \\
\hline 315 & $o$-PFS & $3.0 \%$ & 135 & 1.924418 & 0.0073 \\
\hline 311 & $o$-PFS & $5.0 \%$ & 135 & 1.680193 & 0.0051 \\
\hline \multicolumn{6}{|c|}{$o$-PFS $+\%$ DET } \\
\hline 314 & $o$-PFS & $1.0 \%$ & 135 & 2.708354 & 0.0131 \\
\hline 317 & $o$-PFS & $3.0 \%$ & 135 & 1.988882 & 0.0078 \\
\hline 314 & $o$-PFS & $5.0 \%$ & 135 & 1.646082 & 0.0053 \\
\hline \multicolumn{6}{|c|}{$o-\mathrm{PFS}+\% \mathrm{DOT}$} \\
\hline 319 & $o$-PFS & $1.0 \%$ & 135 & 2.596675 & 0.0125 \\
\hline 316 & $o$-PFS & $3.0 \%$ & 135 & 2.342013 & 0.0105 \\
\hline 319 & $o$-PFS & $5.0 \%$ & 135 & 1.885021 & 0.0068 \\
\hline \multicolumn{6}{|c|}{$o-\mathrm{PFS}+\% \mathrm{DOP}$} \\
\hline 314 & $o$-PFS & $1.0 \%$ & 135 & 2.146864 & 0.0088 \\
\hline 312 & $o$-PFS & $3.0 \%$ & 135 & 1.855966 & 0.0065 \\
\hline 316 & $o$-PFS & $5.0 \%$ & 135 & 1.616742 & 0.0049 \\
\hline \multicolumn{6}{|c|}{$o-\mathrm{PFS}+\% \mathrm{DBP}$} \\
\hline 318 & $o$-PFS & $1.0 \%$ & 135 & 2.823462 & 0.0148 \\
\hline 315 & $o$-PFS & $3.0 \%$ & 135 & 2.371526 & 0.0112 \\
\hline 313 & $o$-PFS & $5.0 \%$ & 135 & 1.884811 & 0.0073 \\
\hline
\end{tabular}


Table 2. Relative intensities of the excimer ratio $\left(\mathrm{I}_{\mathrm{EX}}^{\mathrm{o}} / \mathrm{I}_{\mathrm{EX}}\right)$, and fluorescence photo quenching rate constant values $\left(k_{\mathrm{PQ}}\right)$ of irradiated pure and blended $(m-\mathrm{PFS})$ films

\begin{tabular}{|c|c|c|c|c|c|}
\hline$\lambda_{\text {(emiss.) }}(\mathrm{nm})$ & Polymer & Plasticizer (\%) & Time (min.) & $\left(\mathrm{I}_{\mathrm{EX}}^{\mathrm{o}} / \mathrm{I}_{\mathrm{EX}}\right)$ & $k_{\mathrm{PQ}}$ \\
\hline 313 & $m$-PFS & $0.0 \%$ & 135 & 4.102128 & 0.0247 \\
\hline \multicolumn{6}{|c|}{$m-\mathrm{PFS}+\% \mathrm{DMT}$} \\
\hline 313 & $m$-PFS & $1.0 \%$ & 120 & 3.266168 & 0.0202 \\
\hline 317 & $m$-PFS & $3.0 \%$ & 135 & 2.753010 & 0.0136 \\
\hline 323 & $m$-PFS & $5.0 \%$ & 135 & 2.458003 & 0.0113 \\
\hline \multicolumn{6}{|c|}{$m-\mathrm{PFS}+\% \mathrm{DET}$} \\
\hline 313 & $m$-PFS & $1.0 \%$ & 135 & 3.093906 & 0.0164 \\
\hline 312 & $m$-PFS & $3.0 \%$ & 135 & 2.768698 & 0.0143 \\
\hline 322 & $m$-PFS & $5.0 \%$ & 135 & 2.101375 & 0.0087 \\
\hline \multicolumn{6}{|c|}{$m-\mathrm{PFS}+\% \mathrm{DOT}$} \\
\hline 316 & $m$-PFS & $1.0 \%$ & 135 & 3.976094 & 0.0232 \\
\hline 314 & $m$-PFS & $3.0 \%$ & 135 & 2.573050 & 0.0126 \\
\hline 321 & $m$-PFS & $5.0 \%$ & 135 & 2.116865 & 0.0093 \\
\hline \multicolumn{6}{|c|}{$m-\mathrm{PFS}+\%$ DOP } \\
\hline 314 & $m$-PFS & $1.0 \%$ & 135 & 3.455534 & 0.0195 \\
\hline 312 & $m$-PFS & $3.0 \%$ & 135 & 2.984113 & 0.0160 \\
\hline 312 & $m$-PFS & $5.0 \%$ & 135 & 2.645114 & 0.0133 \\
\hline \multicolumn{6}{|c|}{$m$-PFS $+\%$ DBP } \\
\hline 313 & $m$-PFS & $1.0 \%$ & 135 & 3.203092 & 0.0173 \\
\hline 314 & $m$-PFS & $3.0 \%$ & 135 & 2.891364 & 0.0154 \\
\hline 312 & $m$-PFS & $5.0 \%$ & 140 & 2.656847 & 0.0132 \\
\hline
\end{tabular}


Table 3. Relative intensities of the excimer ratio $\left(\mathrm{I}^{\mathrm{o}}{ }_{\mathrm{EX}} / \mathrm{I}_{\mathrm{EX}}\right)$, and fluorescence photo quenching rate constant values $\left(k_{\mathrm{PQ}}\right)$ of irradiated pure and blended $(p$-PFS) films

\begin{tabular}{|c|c|c|c|c|c|}
\hline$\lambda_{\text {(emiss.) }}(\mathrm{nm})$ & Polymer & Plasticizer (\%) & Time (min.) & $\left(\mathrm{I}_{\mathrm{EX}}^{\mathrm{o}} / \mathrm{I}_{\mathrm{EX}}\right)$ & $k_{\mathrm{PQ}}$ \\
\hline 321 & p-PFS & $0.0 \%$ & 150 & 4.142097 & 0.0216 \\
\hline \multicolumn{6}{|c|}{$p$-PFS $+\%$ DMT } \\
\hline 331 & $p$-PFS & $1.0 \%$ & 135 & 2.648200 & 0.0122 \\
\hline 333 & $p$-PFS & $3.0 \%$ & 135 & 2.055637 & 0.0081 \\
\hline 340 & $p$-PFS & $5.0 \%$ & 135 & 1.775363 & 0.0060 \\
\hline \multicolumn{6}{|c|}{$p$-PFS $+\%$ DET } \\
\hline 332 & $p$-PFS & $1.0 \%$ & 135 & 2.231336 & 0.0092 \\
\hline 335 & $p$-PFS & $3.0 \%$ & 135 & 1.961414 & 0.0071 \\
\hline 336 & $p$-PFS & $5.0 \%$ & 135 & 1.852136 & 0.0064 \\
\hline \multicolumn{6}{|c|}{$p$-PFS $+\%$ DOT } \\
\hline 331 & $p$-PFS & $1.0 \%$ & 135 & 2.323716 & 0.0100 \\
\hline 330 & $p$-PFS & $3.0 \%$ & 135 & 1.962066 & 0.0076 \\
\hline 335 & $p$-PFS & $5.0 \%$ & 135 & 1.804637 & 0.0062 \\
\hline \multicolumn{6}{|c|}{$p$-PFS $+\%$ DOP } \\
\hline 326 & $p$-PFS & $1.0 \%$ & 135 & 2.677273 & 0.0130 \\
\hline 327 & $p$-PFS & $3.0 \%$ & 135 & 2.386828 & 0.0105 \\
\hline 334 & $p$-PFS & $5.0 \%$ & 135 & 1.767196 & 0.0062 \\
\hline \multicolumn{6}{|c|}{$p$-PFS $+\%$ DBP } \\
\hline 321 & $p$-PFS & $1.0 \%$ & 135 & 2.842446 & 0.0154 \\
\hline 329 & $p$-PFS & $3.0 \%$ & 135 & 2.656185 & 0.0130 \\
\hline 324 & $p$-PFS & $5.0 \%$ & 150 & 2.565449 & 0.0111 \\
\hline
\end{tabular}

As can be seen from Tables (1-3), the efficiency of the fluorescence photo-quenching rate constant $k_{P Q}$ was found to decrease with the increase in added amount of plasticizers and with the increase in time of irradiation. It has been reported that the thermal stability of polystyrene was reduced by the addition of polymeric additives (Al Ani, Ramadhan, \& Ahmed 2006), which depends on the chemical structure of the additive. Chain scissions, and changes in the molecular weight distribution, were the main reactions resulted from the photooxidation of irradiated plasticized PS films (Rabek \& Ranby, 1974).

The presence of plasticizer molecules in the polymer matrix was found to cause a lowering in the activation energy during the thermal degradation of poly (para-methoxystyrene) films (Al Ani \& Suleiman, 2007). It was attributed to the lowering in the charge transfer character of the excimer conformation. As can be seen from 
Tables (1-3), the photo quenching of excimer fluorescence was increased with the increase in molar mass of the used terephthalate plasticizers, a fact that correlates well with that obtained for the thermal degradation of plasticized poly (para-methoxystyrene) solid films. The trend of increase in the efficiency of excimer fluorescence quenching is DOT $>$ DET $>$ DMT. Phthalate plasticizers, DBP and DOP showed higher efficiency of photo quenching than what was obtained by terephthalate plasticizers. This behavior may indicate that there is a higher stability for the [terephthalate-PFS]* excited complex than that of [phthalate-PFS]* excited complex It is more likely that the bulkiness of the doped plasticizer molecules can lower the stability of the formed energy transfer complex, and also to the exciplex activation energy for exciplex formation of charge transfer character.

\subsection{FT-IR Spectra for Non-Irradiated and Irradiated Pure and Blended (PFS) Isomers in Solid Films}

In order to confirm the presence of degradation in the irradiated pure and blended PFS isomers, FT-IR spectra were recorded of non-irradiated and irradiated $o$-PFS, $m$-PFS and $p$-PFS film under atmospheric oxygen, and at $298 \mathrm{~K}$. Figure 7, shows the FT-IR spectra of non-irradiated and irradiated for $135 \mathrm{~min}$ of PFS-isomers in solid films in presence of atmospheric oxygen. The effect of irradiation to the films of these isomers is the increase in the intensity of some absorption bands, and the formation of new bands as a result of the photodegradation and photo oxidation processes.

It was noted that the most demonstrated trend is the increase of the absorbance bands at $\left(3800-3000 \mathrm{~cm}^{-1}\right)$, and by the formation of new absorption bands corresponding to new compounds resulting from the polymer chains photodegradation in different regions of the spectra. The following bands are found to refer to the following functional groups, in which several authors reported the formation of absorption bands in the range (3600-3400 $\mathrm{cm}^{-1}$ ), are attributed to formation of the hydroxyl group. They are formed only in the presence of air (oxygen) and are probably due to oxidized benzene rings in polystyrene macromolecules (Rabek \& Ranby, 1974).

The absorption bands in the range of $\left(3100-2800 \mathrm{~cm}^{-1}\right)$, refers to the formation of C-H stretching vibration in the aliphatic chain, and in the aromatic rings. The FT-IR bands in the range of $\left(1700-1600 \mathrm{~cm}^{-1}\right)$ is assigned to a $\mathrm{C}=$ O vibration (Bera, Rivaton, Gandon, \& Gardette, 2000). In the infrared spectra of the photooxidized PFS isomers, we noticed the formation of $825 \mathrm{~cm}^{-1}$ band, which was attributed to conjugated double bond sequences in the main polymer chain (Torikai, Takeuchi, \& Fueki, 1986; Grassie \&. Wier, 1965). While the bands in the range of $\left(1400-600 \mathrm{~cm}^{-1}\right)$, considered to be a deformation vibration region.

As can be seen from the Figure 7 and Table 4, that the hydroxyl stretching vibration region showed the growth of a broad band between $\left(3450\right.$ and $\left.3000 \mathrm{~cm}^{-1}\right)$, centered at $3446 \mathrm{~cm}^{-1}$ for $o$-PFS, at $3441 \mathrm{~cm}^{-1}$ for $m$-PFS and at $3416 \mathrm{~cm}^{-1}$ for $p$-PFS, which are corresponding to hydroxyl groups associated with carboxylic acids. The decrease in the range $\left(3600-3400 \mathrm{~cm}^{-1}\right)$ for $o$-PFS in comparison with increase in the other two isomers is may be attributed to the increase in the formation of conjugated double-bond sequences in the main polymer chain.

An increase of the bands at $\left(3057,2934\right.$ and $\left.2852 \mathrm{~cm}^{-1}\right)$ for $o$-PFS, at $\left(3067,2924\right.$ and $\left.2852 \mathrm{~cm}^{-1}\right)$ for $m$-PFS, and at $\left(3037,2924\right.$ and $\left.2852 \mathrm{~cm}^{-1}\right)$ for $p$-PFS, can be assigned to the formation of more double bonds or to the increase in the aromatic structure of the polymer backbone, and also can be attributed to the deformation and skeletal vibration of C-H in PFS isomers. 

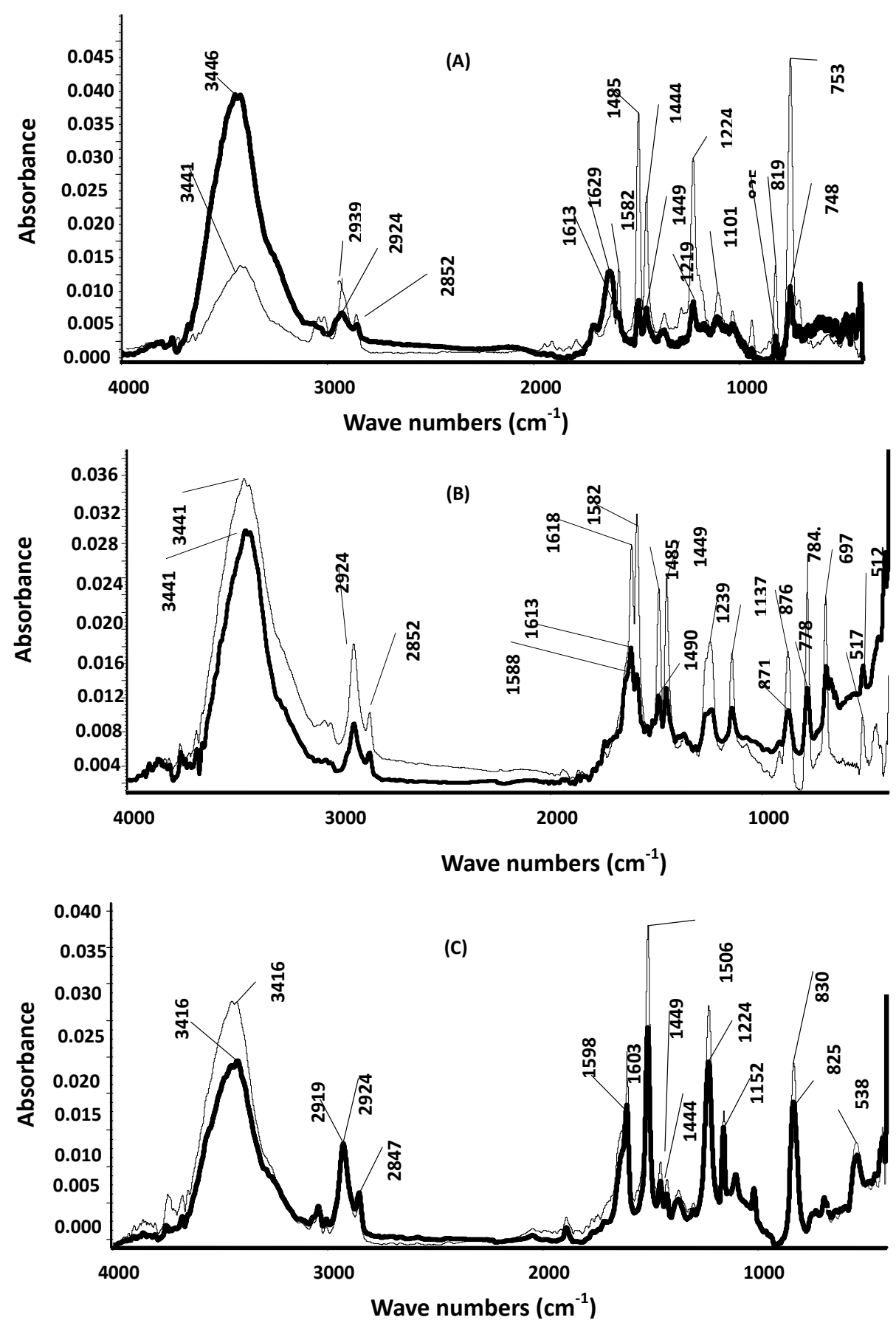

Figure 7. FT-IR spectra of non-irradiated (solid line) and irradiated (fade line) for $135 \mathrm{~min}$, solid films of (A) $o$-PFS, (B) $m$-PFS and (C) $p$-PFS, at $298 \mathrm{~K}$ 
Table 4. FT-IR band position in $o$-PFS, $m$-PFS and $p$-PFS, before and after $(0.0 \mathrm{~min}$ and $135 \mathrm{~min})$ irradiation

\begin{tabular}{|c|c|c|c|c|}
\hline Band $\left(\mathrm{cm}^{-1}\right)$ & $0.0 \mathrm{Min}$ & 135 Min & Type of vibration & Intensity \\
\hline \multirow{9}{*}{$o$-PFS } & 3446 & 3441 & $(\mathrm{OH})$, stretching vibration of carboxylic acid & Dec. \\
\hline & 2924 & 2924 & $(\mathrm{C}-\mathrm{H})$, stretching vibration of benzene & Inc. \\
\hline & 2852 & 2852 & $\mathrm{C}-\mathrm{H}$ of aldehyde & Inc. \\
\hline & 1629 & 1629 & $\mathrm{C}=\mathrm{C}$ stretch & Dec. \\
\hline & 1588 & 1588 & \multirow{2}{*}{$(\mathrm{C}=\mathrm{O})$ stretching of aromatic ketones } & \multirow{2}{*}{ Inc. } \\
\hline & 1485 & 1485 & & \\
\hline & 1449 & 1449 & $\left(\mathrm{CH}_{2}\right)$ Methylene bend & Inc. \\
\hline & 1219 & 1219 & $\mathrm{C}-\mathrm{O}-\mathrm{C}$ stretching vibration & Inc. \\
\hline & 825 & 825 & Conjugated double bond & Inc. \\
\hline \multirow{9}{*}{ m-PFS } & 3441 & 3441 & $(\mathrm{OH})$, stretching vibration of carboxylic acid & Inc. \\
\hline & 2924 & 2924 & $(\mathrm{C}-\mathrm{H})$, stretching vibration of benzene & Inc. \\
\hline & 2852 & 2852 & $\mathrm{C}-\mathrm{H}$ of aldehyde & Inc. \\
\hline & 1613 & 1618 & $\mathrm{C}=\mathrm{C}$ stretch & Inc. \\
\hline & 1588 & 1582 & \multirow{2}{*}{$(\mathrm{C}=\mathrm{O})$ stretching of aromatic ketones } & \multirow{2}{*}{ Inc. } \\
\hline & 1490 & 1485 & & \\
\hline & 1449 & 1449 & $\left(\mathrm{CH}_{2}\right)$ Methylene bend & Inc. \\
\hline & 1239 & 1239 & $\mathrm{C}-\mathrm{O}-\mathrm{C}$ stretching vibration & Inc. \\
\hline & 871 & 876 & Conjugated double bond & Inc. \\
\hline \multirow{8}{*}{$p$-PFS } & 3416 & 3416 & $(\mathrm{OH})$, stretching vibration of alcohol & Inc. \\
\hline & 2924 & 2919 & $(\mathrm{C}-\mathrm{H})$, stretching vibration of benzene & Inc. \\
\hline & 2852 & 2847 & $\mathrm{C}-\mathrm{H}$ of aldehyde & Inc. \\
\hline & 1598 & 1603 & $\mathrm{C}=\mathrm{C}$ stretch & Inc. \\
\hline & 1506 & 1506 & $(\mathrm{C}=\mathrm{O})$ stretching of aromatic ketones & Inc. \\
\hline & 1444 & 1449 & $\left(\mathrm{CH}_{2}\right)$ Methylene bend & Inc. \\
\hline & 1224 & 1224 & $\mathrm{C}-\mathrm{O}-\mathrm{C}$ stretching vibration & Inc. \\
\hline & 825 & 830 & Conjugated double bond & Inc. \\
\hline
\end{tabular}

Photooxidation of irradiated PFS-isomers leads to increase in the intensity of absorbance in the bands with noticeable shift of energy at $\left(1582-1449 \mathrm{~cm}^{-1}\right)$ for $o$-PFS, at $\left(1588-1449 \mathrm{~cm}^{-1}\right)$ for $m$-PFS and at $\left(1506 \mathrm{~cm}^{-1}\right)$ for $p$-PFS. The shift in these ranges can be attributed either to the $\mathrm{C}=\mathrm{O}$ stretching vibration of aromatic ketones, or to the stretching vibration of the substituted benzene ring (Millan, Locklin, Fulghum, Baba, \& Advincula, 2003).

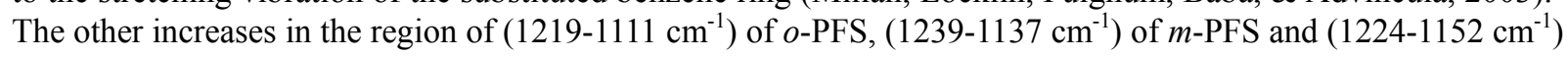
of $p$-PFS, indicates that there is an increase in the number of $\mathrm{C}=\mathrm{C}$ that resulted from hydrogen abstraction during chains scission process, or as indicated in the Table 5, it results from the $(\mathrm{C}-\mathrm{O}-\mathrm{C})$ stretching vibration. As we mentioned previously that the increase of the absorption bands at $819 \mathrm{~cm}^{-1}$ for (o-PFS and $p$-PFS), and at $876 \mathrm{~cm}^{-1}$ for $m$-PFS, and $825 \mathrm{~cm}^{-1}$ for $o$-PFS, indicates the formation of conjugated double bond sequences in the main polymer chain. The increase in the FT-IR absorption band at $1629 \mathrm{~cm}^{-1}$ for $o$-PFS and at $1613 \mathrm{~cm}^{-1}$ for $m$-PFS may indicate modifications in ring substitution; it means that the aromatic rings lose their symmetry throughout photooxidation processes (Al Ani \& Hawi, 2009; Al Ani \& Ramadhan, 2010b). The increase in the absorption intensity of these bands indicated that the formed products were resulted from an extensive chain scission due to UV exposure, followed by an oxidation of formed fragments due to the presence of oxygen during irradiation. We noted that most of peak positions are changed, which indicates that the photo-degraded products are not the same during the degradation process.

It has been reported that the rate of photooxidative degradation of ethylene/propylene (Ferry et al., 2012), and 
Ethylene/Styrene Copolymers (Fernandez et al., 2007), caused by polychromic irradiation $(\lambda \geq 290 \mathrm{~nm})$ at $55^{\circ} \mathrm{C}$ in atmospheric air is reduced in copolymers containing aromatic systems. In the same way, introducing aromatic rings into aliphatic compounds increases their stability. It was assumed that the aromatic moiety, which is very radiation resistant, accommodates the extra energy remaining unaffected.

The FT-IR spectra of non-irradiated and irradiated PFS-isomers solid films which blended with different plasticizers were recorded at $298 \mathrm{~K}$, and at $\lambda=265 \mathrm{~nm}$ in the presence of oxygen, and is recorded before and after irradiation for $135 \mathrm{~min}$, as shown in (Figure 8, Figure $9 \&$ Figure 10).
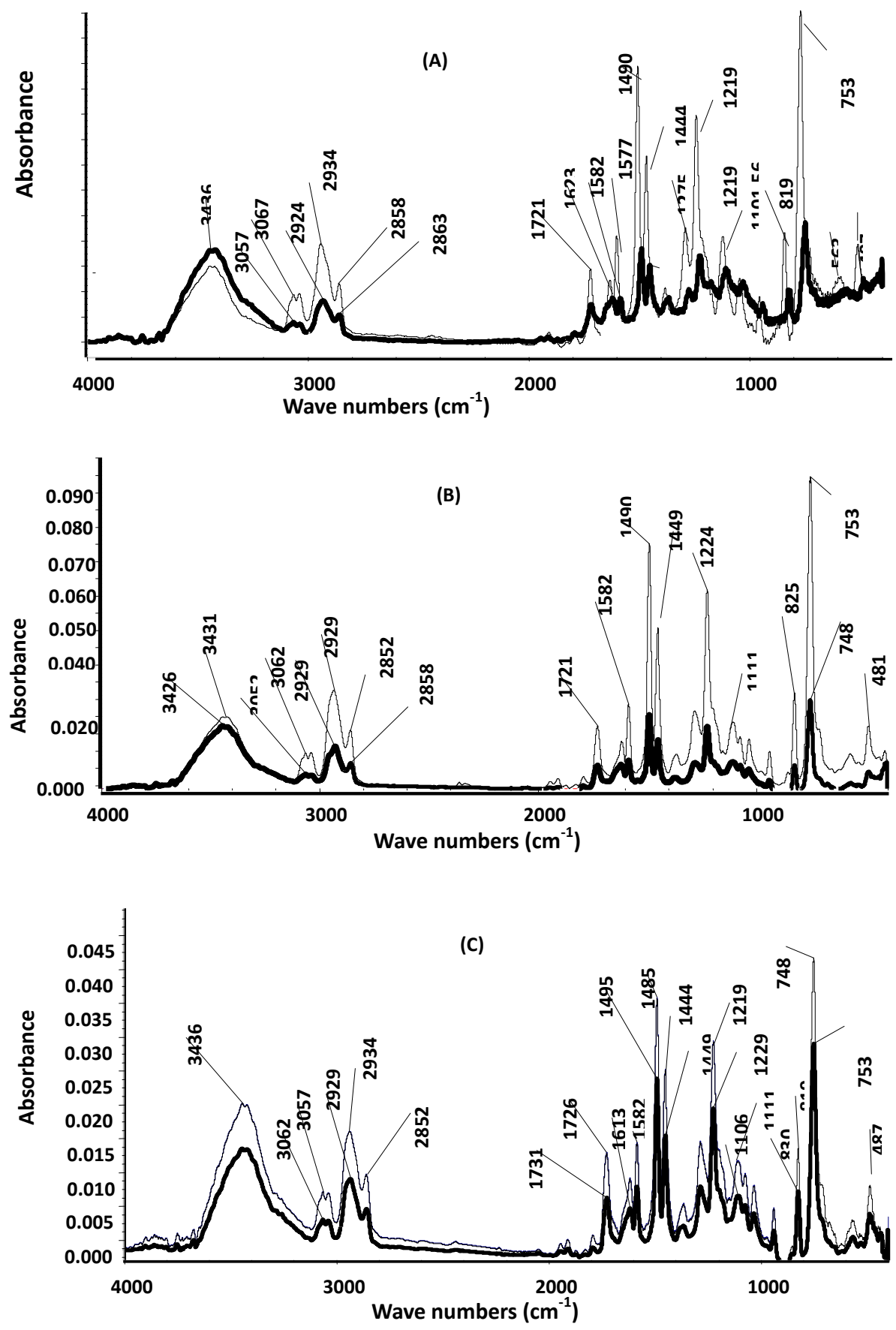

Figure 8. FT-IR spectra of non-irradiated (solid line) and irradiated for 135 min (fade line) of $o$-PFS solid films blended with (A) DET $5 \%$, (B) DOP $5 \%$ and (C) DBP $5 \%$, at $298 \mathrm{~K}$ 

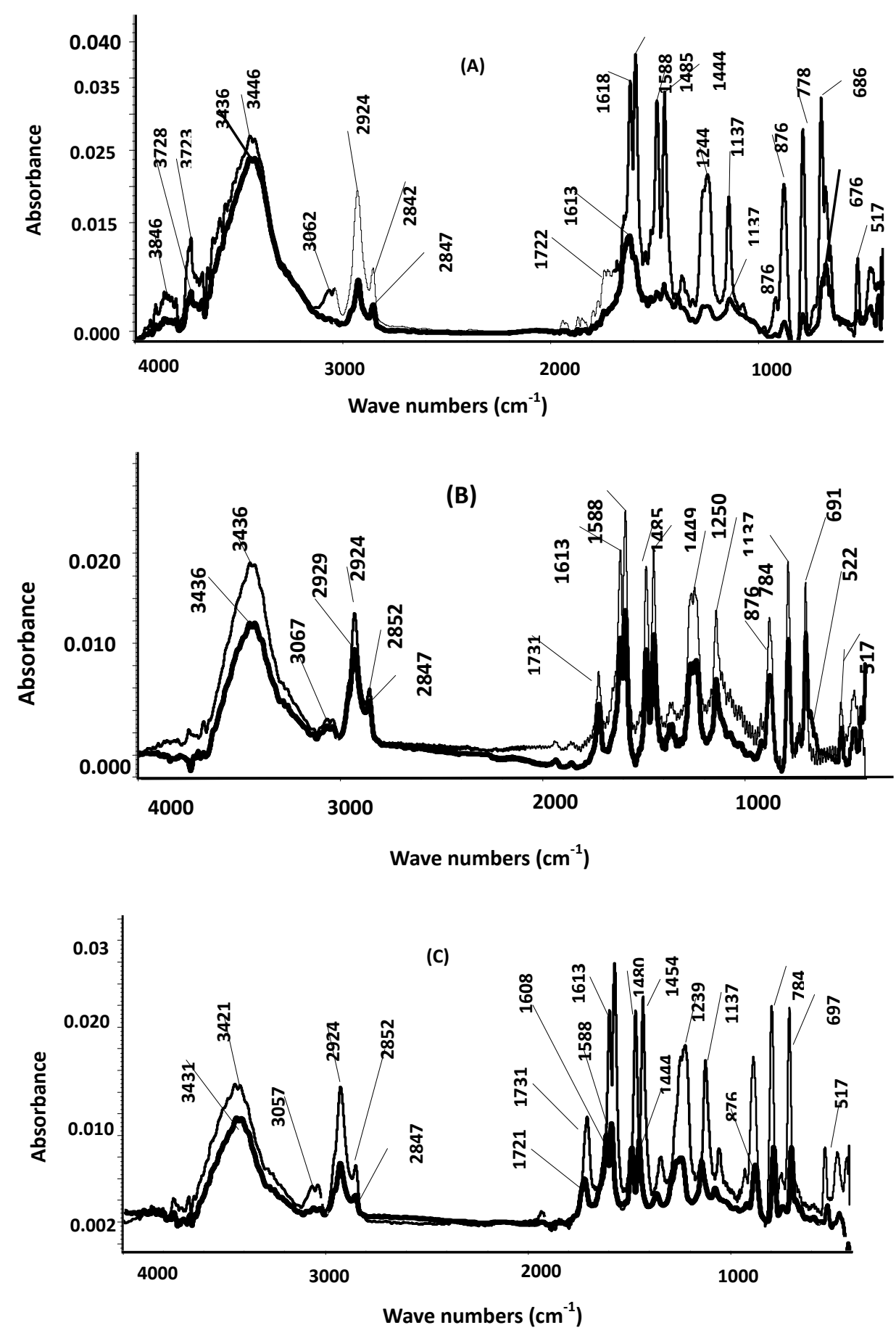

Figure 9. FT-IR spectra of non-irradiated (solid line) and irradiated for $135 \mathrm{~min}$ (fade line) of $m$-PFS solid films blended with (A) DET $5 \%$, (B) DOP $5 \%$ and (C) DBP $5 \%$, at 298K 

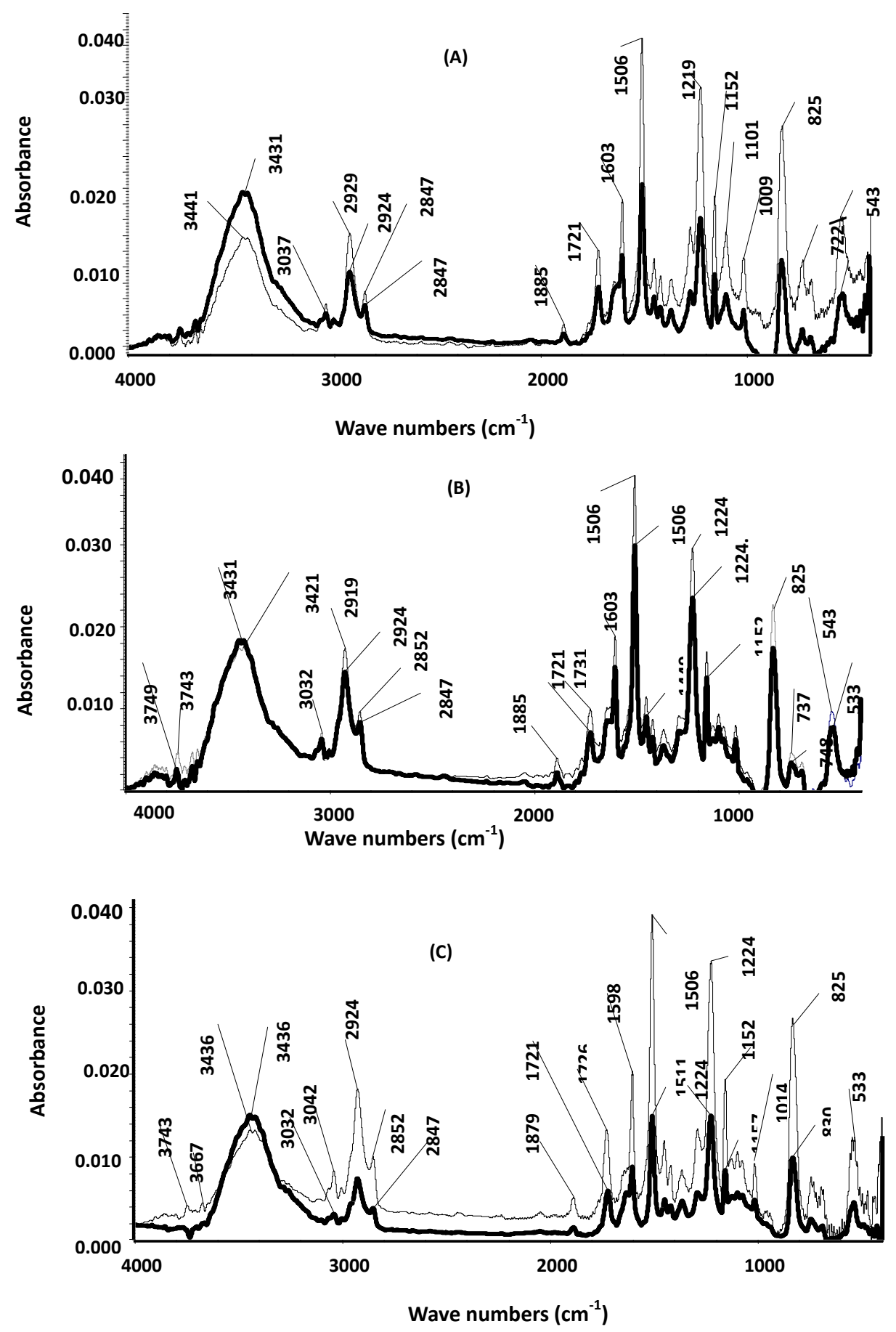

Figure 10. FT-IR spectra of non-irradiated (solid line) and irradiated for 135 min (fade line) of $p$-PFS solid films blended with (A) DET $5 \%$, (B) DOP $5 \%$ and (C) DBP $5 \%$, at $298 \mathrm{~K}$

We can notice that the degradation products for irradiated pure PFS isomers are not the same as that for irradiated blended polymer films. As can be seen from (Figure 8, Figure $9 \&$ Figure 10), the general trend of irradiating blended PFS-isomers showed an increase in most of absorbance bands, with a noticeable shift in the energy in most of peaks. All blended PFS isomers with phthalate and terephthalate plasticizers showed a noticeable formation of new IR absorbance bands at the range of $\left(1885-1700 \mathrm{~cm}^{-1}\right)$.

An increase of the absorbance in most of the bands that appeared by blending $o$-PFS with different plasticizers, is clearly noticed in Figure 8. Plasticizing $o$-PFS with DET showed a new band at $1623 \mathrm{~cm}^{-1}$, while blending it with DOP and DBP showed an increase of new band at $\left(1721-1731 \mathrm{~cm}^{-1}\right)$. In the case of plasticizing $m$-PFS with 
DET showed the appearance of a new band at $1722 \mathrm{~cm}^{-1}$. FT-IR spectra of $p$-PFS showed more new bands upon blending it with DET, DOP and DBP, in which new band at $1879 \mathrm{~cm}^{-1}$, and at $2852 \mathrm{~cm}^{-1}$ and $3042 \mathrm{~cm}^{-1}$ were observed, in blending PFS-isomers with DBP. Those new bands (at $1722 \mathrm{~cm}^{-1}$ ) may be attributed to the formation of oxygenated fragments resulted from the photodegradation process. It is generally accepted to refer the absorption band for $\mathrm{C}=\mathrm{O}$ stretching vibration to saturated and unsaturated ketones and aldehydes (Pouchert, 1985).

The other observation in the IR-spectra of PFS-isomers, is the large increase in the absorption in the region (1600-825 $\left.\mathrm{cm}^{-1}\right)$, in comparing with that of unblended PFS isomers films. This may indicate that there is an increase in the number of $(\mathrm{C}=\mathrm{C})$ that resulted from hydrogen abstraction during chain scission process.

A noticeable increase in the FT-IR peaks of irradiated $o$-PFS at $748 \mathrm{~cm}^{-1}$ by blending it with DET, DOP and an increase in the peak at $753 \mathrm{~cm}^{-1}$ by blending with DBP. While in the case of $m$-PFS, a noticeable increase in the peaks at $784 \mathrm{~cm}^{-1}$ in blending with all plasticizers was observed. It was also observed an increase in the absorption band at $676 \mathrm{~cm}^{-1}$ by blending $m$-PFS with DMT, and at $697 \mathrm{~cm}^{-1}$ in blending with both DOT and DBP. The intensity of these bands increased with blending of the solid films of these isomers, indicating a less stability of the blended polymer toward UV-irradiation.

In general we noticed that the FT-IR spectra of PFS isomers showed a noticeable change upon irradiation of pure polymer and upon plasticization. Some peaks were appearing; other peaks showed an increase in the absorption intensity, while others showed a decrease. The pure PFS isomers and the blended PFS isomers spectra, recorded after 135 min of irradiation, permit characterizing these modifications as follows:

(1) At high region of the FT-IR spectra, the bands at $3446 \mathrm{~cm}^{-1}$ for $o$-PFS, at $3441 \mathrm{~cm}^{-1}$ for $m$-PFS and at 3416 $\mathrm{cm}^{-1}$ for $p$-PFS, a noticeable decrease in the absorption bands is observed in blended polymers; on the other hand, a very small decrease was observed in the irradiated pure polymer and can be attributed to the hydroxyl group associated with carboxylic acid.

(2) The spectra of PFS isomers showed a broad band with two broad shoulders at $2924 \mathrm{~cm}^{-1}$ and $2852 \mathrm{~cm}^{-1}$, assigned to the $(\mathrm{C}-\mathrm{H})$, stretching vibration of benzene, those bands were found to increase with the increase of irradiation time and with the increase in the amount of used plasticizer. This result can be attributed to the photodegradation of PFS isomers involving the oxidation of benzene rings (Bera, Rivaton, Gandon, \& Gardette, 2000).

(3) By blending PFS isomers with plasticizers of different percentages, a noticeable formation of new broad band centered at $1722 \mathrm{~cm}^{-1}$, and its intensity was found to increase with the increase in irradiation time and also with the increase in the amount of added plasticizer, this could be attributed to the formation of oxidized products resulted from photodegradation (Pouchert, 1985).

(4) The major increase of the bands, $\left(1495,1454,1224,1219 \mathrm{~cm}^{-1}\right)$ for $o$-PFS, at $\left(1485,1444,1244,1137 \mathrm{~cm}^{-1}\right)$ for $m$-PFS, and at $\left(1219,1224,1152 \mathrm{~cm}^{-1}\right)$ for $p$-PFS suggests the formation of mono-substituted benzene rings (Bera, Rivaton, Gandon \& Gardette, 2000).

(5) We observed an absorbance band at $825 \mathrm{~cm}^{-1}$, as can be noted in all the spectra, which suggests the formation of conjugated double bond sequences in the main polymer chain. The same band was observed by Grassie and Weir on photooxidation of polystyrene (Grassie \& Weir, 1965).

We may come out with the conclusion from the reported data of UV-absorption, fluorescence and FT-IR spectra that the destruction of polymeric chains occurs as a result of the formation of free radicals, which in the presence of oxygen molecules form proxy radicals that create chain scission in polymer backbone. We can summarize the conclusions that can be gathered from this research work.

\section{Conclusions}

Based on the obtained data of effect of UV-exposure time, blending with phthalate and terephthalate plasticizers, and fluorescence quenching for the irradiated plasticized and non-plasticized ( $o$-PFS), $(m-\mathrm{PFS})$ and ( $p$-PFS) solid films and from the changes in the FT-IR spectra of irradiated pure and blended PFS isomers the following conclusions can summarize as:

(1) Irradiation of pure PFS isomers, and also blended polymers in the presence of oxygen resulted in the enhancing of the absorption spectra, and this increases by increase in time of exposure. Another observation is the formation of new absorption band at longer wavelength, indicating the formation of new compounds resulting from the photodegradation of irradiated polymers.

(2) Irradiation of blended PFS isomers films with terephthalate and phthalate plasticizers showed that 
terephthalate additives caused less degradation effect in comparing with that of phthalate plasticizers. The degradation effect was found to increase by the increase in bulkiness of the plasticizer molecule.

(3) From the FT-IR spectra of irradiated PFS-isomers solid film, a noticeable change was observed by the formation of new absorption band, as well as, the change in the intensity of many bands (decrease of some and increase of most of the others) in the FT - IR spectrum. This clearly indicates the possibility of photodegradation of the polymeric chains, and this change increases with the increase in time of irradiation.

\section{References}

Al Ani, K. E., \& Hawi, M. (2009). Effect of plasticization on the photodegradation of poly (p- methoxystyrene) films. J. Mater. Sci., 44(10), 2674-2681. http://dx.doi.org/10.1007/s10853-009-3350-x

Al Ani, K. E., \& Ramadhan, A. E. (2008). Photodegradation of poly (para-substituted styrene) in solution. Polym. Degrad. Stab., 93(8), 1590-1596. http://dx.doi.org/10.1016/j.polymdegradstab.2008.04.010

Al Ani, K. E., \& Ramadhan, A. E. (2010). Plasticization effect on the photodegradation of poly (4- chlorostyrene) and poly (4-bromostyrene) films. Materials Sciences and Applications, 1(4), 358-368. http://dx.doi.org/10.4236/msa.2010.16052

Al Ani, K. E., \& Ramadhan, A. E. (2010). Study of the influence of UV-irradiation on the photodegradation of plasticized ploy (para-tert-butylstyrene) films. Int. J. Mater. Res., 101(12), 1554-1562. http://dx.doi.org/10.3139/146.110434

Al Ani, K. E., \& Suleiman, A. M. (2007). Substituent effect on fluorescence quenching of polystyrene derivatives by polymeric plasticizers. J. Photochem. Photobiol. A Chem., 188(2), 177-184. http://dx.doi.org/10.1016/j.jphotochem.2006.12.010

Al-Ani, K. E., Ramadan, A. E., \& Ahmed, R. H. (2006). Thermal effect and Quenching of exciplex Fluorescence of Polystyrene derivatives by Dimethyl terephthalate in solid films and solutions. Polymer Journal, 38, 355-363. http://dx.doi.org/10.1295/polymj.38.355

Beak, P., \& Messer, W. R. (1969). Organic Photochemistry, Vol. 2. New York: Dekker.

Bera, M., Rivaton, A., Gandon, G., \& Gardette, J. L. (2000). Photo-oxidation of poly (p-xylene). Eur. olym. J., 36(9), 1753-1764. http://dx.doi.org/10.1016/S0014-3057(99)00258-X

Bertini, F., Audisio, G., \& Kiji, J. (1995). Thermal behavior and degradation mechanism of brominated polystyrenes. J. Anal. Appl. Pyrolysis, 33(1), 213 - 230. http://dx.doi.org/10.1016/0165-2370(94)00836-P

Bertini, F., Audisio, G., \& Kiji, J. (1995). Thermal degradation of chlorinated polystyrenes. J. Anal. Appl. Pyrolysis, 28(2), 205 - 217. http://dx.doi.org/10.1016/0165-2370(93)00774-H

Boinon, B., Ainad-Tabet, D., \& Montheard, J. P. (1990). Thermal degradation of poly (o-chlorostyrene and poly (m-chlorostyrene). Polym. Degrad. Stab., 28(2), 197-207. http://dx.doi.org/10.1016/0141-3910(90)90006-S

Choi, W. M., Jung, I. D., Sik, C., \& Cho, W. (1998). Synthesis and properties of photodegradable polystyrene-containing carbonyl group. J. Appl. Polym. Sci., 67(7), 1237-1242. http://dx.doi.org/10.1002/(SICI)1097-4628(19980214)67:7<1237::AID-APP11>3.0.CO;2-Z

David, C., Baeyens-Volant, D., Delaunois, G., Lu Vinh, Q., Piret, W., \& Geuskens, G. (1978). Photo-oxidation of polymers: III-Molecular weight changes in the photolysis and photo-oxidation of polystyrene. Eur. Polym. J., 14(7), 501-507. http://dx.doi.org/10.1016/0014-3057(78)90037-X

Grassie, N., \& Wier, N. A. (1965). The photo-oxidation of polymer. II. Photolysis of polystyrene. J. ppl. Polym. Sci., 9(3), 975-986. http://dx.doi.org/10.1002/app.1965.070090315

Kaczmarek, H. (1995). Photodegradation of polystyrene and poly (vinyl acetate) blends. II. Irradiation of PS/PVAc blends by fluorescent lamp. Eur. Polym. J., 31(12), 1175-1184. http://dx.doi.org/10.1016/0014-3057(95)00095-X

Lacoste, J., Carlson, D. J., Falicki, S., \& Wiles, M. D. (1994). Polyethylene hydroperoxide decomposition products. Polym. Degrad. Stab., 34(3), 309-323. http://dx.doi.org/10.1016/0141-3910(91)90125-B

Lucas, P. C., \& Porter, R. S. (1989). Auto inhibition in polystyrene photo-oxidation. Polym. Degrad. Stab., 26(3), 203-208. http://dx.doi.org/10.1016/0141-3910(89)90073-6

Lucki, J., Rabek, J. F., Ramby, B. J., \& Jiang, Y. C. (1986). Polymer, 27.1193. http://dx.doi.org/10.1016/0032-3861(86)90007-8 
Mailhot, B., Jarroux, N., \& Gardette, J. L. (2000). Comparative analysis of the photo-oxidation of polystyrene and poly ( $\alpha$-methylstyrene). Polym. Degrad. Stab., 68(3), 321-326. http://dx.doi.org/10.1016/S0141-3910(00)00016-1

McNeill, I. C., \& Coskun, M. (1987). Structure and stability of halogenated polymers; Part 2-Ring chlorinated polystyrene. Polym. Degrad. Stab., 18(3), 213-224. http://dx.doi.org/10.1016/0141-3910(87)90002-4

McNeill, I. C., \& Coskun, M. (1989). Structure and stability of halogenated polymers; Part 3-Ring brominated polystyrene. Polym. Degrad. Stab., 23(2), 175-183. http://dx.doi.org/10.1016/0141-3910(89)90086-4

Millan, M. D., Locklin, J., Fulghum, T., Baba, A,. \& Advincula, R. C. (2003). Polymer thin film photodegradation and photochemical cross-linking FT-IR imaging evanescent waveguide spectroscopy, and QMC investigation. Polymer, 46(15), 5556-5568. http://dx.doi.org/10.1016/j.polymer.2005.05.050

Pouchert, C. J. (Ed). (1985). The Aldrich library of Infra-Red spectra (3rd ed). Milwaukee, WI: Aldrich Co.

Rabek, J. F., \& Ranby, B. (1974). Studies on the photo-oxidation mechanism of polymers, I. Photolysis and photooxidation of polystyrene. J. Polym. Sci. Polym. Chem. Ed., 12(2), 273-294. http://dx.doi.org/10.1002/pol.1974.170120203

Rabek, J. F. (1995). Polymer Photodegradation. Mechanisms and experimental methods. London: Chapman and Hall.

Rao, C. N. R. (1975). Ultraviolet and Visible Spectroscopy (3rd ed.). London: Butterworth.

Subramanian, K. (2002). Photodecomposition of poly (styrene peroxide). Eur. Polym. J., 38(6), 1167-1173. http://dx.doi.org/10.1016/S0014-3057(01)00297-X

Szwarc, M. (1976). Poly (p-xylene): Its chemistry and application in coating technology. Polym. Eng. Sci., 16(7), 473-479. http://dx.doi.org/10.1002/pen.760160703

Tamai, T., Hashida, I., Ichinose, N., Kawanishi, S., Inoue, H., \&. Mizuno, K. (1996). UV-irradiation of thin film of polystyrene derivatives: formation of carboxylic group and cross-linking from 4-trimethylsilylmethyl substituent. Polymer, 37(24), 5525-5528. http://dx.doi.org/10.1016/S0032-3861(96)00438-7

Torikai, A., Kobatake, T., Okisaki, F., \& Shuyama, H. (1995). Photodegradation of polystyrene containing fame-retardant wavelength sensitivity and efficiency of degradation. Polym. Degrad. Stab., 50(3), 261-267. http://dx.doi.org/10.1016/0141-3910(95)00143-3

Torikai, A., Takeuchi, A., \& Fueki, K. (1986). The effect of temperature on the photo- degradation of Polystyrene, Polym. Degrad. Stab., 14(4), 367-375. http://dx.doi.org/10.1016/0141-3910(86)90040-6

Jensen, J. P. T., \& Kops, J. J. (1981). Energy transfer connection with the photo-oxidation of polystyrene and its blends with poly (2, 6- dimethyl-1, 4-phenylene oxide). J. Polym. Sci. Polym. Chem. Ed., 19(11), 2765-2771. http://dx.doi.org/10.1002/pol.1981.170191112

Weir, N. A., Arct, J., \& Farahani, M. (1985). The Photolysis of poly (p-hydroxystyrene). Polym. Degrad. Stab., 13(4), 361-375. http://dx.doi.org/10.1016/0141-3910(85)90084-9

Weir, N. A. (1978). Reactions of hydroxyl radical with polystyrene. Eur. Polym. J., 14(1), 9-14. http://dx.doi.org/10.1016/0014-3057(78)90144-1

Weir, N. A., \& Milkie, T. H. (1979a). Photochemistry of ring-substituted polystyrenes. IV. Photolysis of Poly (o, m, p-methylstyrene). Polym. Degrad. Stab., 1(3), 181-191. http://dx.doi.org/10.1016/0141-3910(79)90015-6

Weir, N. A., \& Milkie, T. H. (1979b). Photochemistry of ring-substituted polystyrenes. III. Photolysis of Poly (o, m, p-methylstyrene). Polym. Degrad. Stab., 1(2), 105-120. http://dx.doi.org/10.1016/0141-3910(79)90009-0

Weir, N. A., \& Milkie, T. H. (1979c). Photochemistry of ring-substituted polystyrenes. II. Photolysis of Poly (p-fluoro, p-chloro, and p-bromostyrene)s. J. Polym. Sci. Polym. Chem. Ed., 17(11), 3735-3749. http://dx.doi.org/10.1002/pol.1979.170171129

Weir, N. A., Whiting, K., \& Arct, J. (1990). Studies of poly (o-acetyl styrene). II. Photoreactions of poly (o-acetyl styrene). J. Polym. Sci. Polym. Chem., 28(7), 1935-1945. http://dx.doi.org/10.1002/pola.1990.080280724

Wu, S. K., Liu, L. H., \& Dai, G. S. (1984). Polymer Communications, 2(2), 153-155.

Zuev, V. V., Bertini, F., \& Audisio, G. (2001). Thermal degradation of para-substituted polystyrenes. Polym. Degrad. Stab., 71(2), 213-221. http://dx.doi.org/10.1016/S0141-3910(00)00113-0 